\title{
Ginseng Compound
}

National Cancer Institute

\section{Source}

National Cancer Institute. Ginseng Compound. NCI Thesaurus. Code C125000.

A compound containing the traditional Chinese medicine (TCM) ginseng, a herb belong ing to the Araliaceae family, with potential antioxidant, chemopreventive, anti-inflammatory and antineoplastic activities. Upon administration of the ginseng compound, the active ing redients, mainly ginsenosides, inhibit various signal transduction pathways that play key roles in carcinogenesis and inflammation. This leads to the induction of apoptosis in and inhibits proliferation of tumor cells. In addition, ginsenosides enhance the activity of various antioxidant enzymes, induce nitric oxide (NO) formation, inhibit the formation of reactive oxygen species (ROS) and protect against free radical-induced DNA damage. Ginseng also modulates various components of the immune system, including the activation of dendritic cells (DCs). 